\title{
The effect of carbonate apatite membrane gelatin application on IL-1B level gingival crevicular fluid in chronic periodontitis patients
}

\author{
Indra Mustika ${ }^{*}$, Ina Hendiani ${ }^{1}$, Renaldy Sartiono ${ }^{1}$ \\ ${ }^{1}$ Departement of Periodontics, Faculty of Dentistry Universitas Padjadjaran, Indonesia
}

\begin{abstract}
Introduction: Apatite carbonate material plays an important role in bone tissue regeneration. The use of this membrane is expected to achieve better treatment success than those without additional therapy. The antimicrobial content in the apatite carbonate membrane can be used to support periodontal treatment of chronic periodontitis after scaling and root planing. The purpose of this research was to analyse the effect of carbonate apatite membrane gelatin application on the IL-1B level of the gingival crevicular fluid in chronic periodontitis patients. Methods: This research was a double-blind, randomised controlled trial method, with purposive sampling, and split-mouth design. The parameter was the IL-1B level in the gingival crevicular fluid before and after scaling and root planing. Carbonate apatite membrane gelatin was applied to the periodontal pocket on the test group after scaling and root planing. Data were analysed by the Wilcoxon test with a p-value $<0.05$. Results: The reduction of IL-1B level gingival crevicular fluid on day- 0 and day-30 on both groups showed significant value $(p<0.001)$. However, it showed no significant differences statistically, between the test group and the control group. Conclusion: Carbonate apatite membrane gelatin application might reduce the IL-1B level of the gingival crevicular fluid, but not showing a better reduction from the control group.
\end{abstract}

Keyword: Carbonate apatite membrane gelatin, IL-1B, periodontal therapy

p-ISSN: 1979-0201; e-ISSN: 2549-6212; Available from: http://jurnal.unpad.ac.id/pjd/article/view/23930

DOI: 10.24198/pjd.vol31no3.23930

Submission: Jul 13, 2019; Accepted: Nov 20, 2019; Published online: Nov 30, 2019

\section{INTRODUCTION}

Chronic periodontitis is a chronic inflammation that affects the tooth-supporting tissues resulting in loss of attachment, bone damage, even the tooth loss. Periodontitis has multifactorial aetiology, not only bacteria that can cause periodontal tissue damage. Other factors, such as lifestyle, environment, and genetic factors, also affecting the damage. Periodontitis always begins with gingivitis, progressing to the tooth supporting tissues, which are characterised by gingival inflammation, periodontal pocket deepening, periodontal ligament and alveolar bone damage,

"Corresponding author: Indra Mustika Setia Pribadi, Department of Periodontics, Faculty of Dentistry Universitas Padjadjaran, Indonesia. Sekeloa Selatan No.1 Bandung, Indonesia, 40132. Phone: +628562143662; Email: indra.mustika@ fkg.unpad.ac.id 
which causes teeth to oscillate until eventually loses gradually. ${ }^{1-3}$

The complex chronic inflammatory response to the periodontal tissue involves innate and adaptive immune cells secreted by inflammatory mediators. The balance of inflammatory mediators and host immune response are able to determine the success of the treatment. Inflammatory mediators are activated when bacteria accumulates in the gingival region..$^{2,4,5}$

Interleukin-1 is a term for some cytokine polypeptides, such as IL-1a, IL-1ß, and IL-1ra, which play an essential role in the regulation of the immune system and the inflammatory response. Macrophages or lymphocytes activate interleukin-1; otherwise, it can be produced by other cells, including mast cells, fibroblasts, keratinocytes, and endothelial cells. Interleukin$1 B(\mathrm{IL}-1 \mathrm{~B})$ is more involved in bone metabolism. Some studies suggested that if there are mechanical stress and periodontal tissue damage, the expression of IL-1B can be detected in gingival sulcus fluids, and the level of IL $1-B$ will increase and diffusing into the crevicular fluid. The peak is 24 hours after the stimulus. ${ }^{3,6}$ Measurements of IL-1B levels can be performed using the Enzyme-Linked Immunosorbent Assay (ELISA) method, which is a laboratory tests using specific enzymes. .,7 $^{2}$

Providing local therapy on periodontal pocket using periodontal chips is one of the additional treatment that can be used after scaling and root planing to get better results. The periodontal chips use active ingredients containing chlorhexidine. We have now developed the use of periodontal chips made from apatite carbonate with an antigenic gelatin base. Prior research had suggested that the application of apatite carbonate membrane gelatin affects the proliferation of fibroblasts. Fibroblasts play an important role in the synthesis, deposition, and remodelling of connective tissue. The same material also plays an essential role in the regeneration of bone tissue. ${ }^{8}$ The use of this membrane is expected to achieve better treatment efficacy than without additional therapy ${ }^{9}$, with the 5 , or $15 \% \mathrm{CO}_{2}$-containing $\mathrm{N}_{2}$ atmosphere by a wet-chemical method with a strong ammonia alkali solution of calcium nitrate and diammonium hydrogen phosphate (5:3 in molar ratio). The purpose of this study was to investigate the effect of apatite carbonate membrane gelatin application on the levels of IL-1B in the gingival sulcus fluid of chronic periodontitis patients.

\section{METHODS}

This study used a double-blind method, randomised controlled trial; while the sample was taken with purposive sampling method and the split-mouth technique. The study was approved by the Health Research Ethics Commitee of Universitas Padjadjaran with registry number 882/ UN6.C1.3.2/KEPK/PN/2016 and written informed consent signed by all participants.

The population in this study were male and female patients at the Periodontics Clinic of Universitas Padjadjaran Dental Hospital in the period of September 2016 - January 2017 with a diagnosis of generalised chronic periodontitis.

The inclusion criteria were patients aged 35 65 years with a diagnosis of chronic periodontitis, having at least two caries-free teeth per quadrant with a pocket depth of $\geq 5 \mathrm{~mm}$; while the exclusion criteria were patients with a history of systemic disease, smoking habits, taking medication (antibiotics, inflammation, mouthwash) for the last three months. Patients who had received a root planing treatment six months earlier and using a prosthesis or orthodontic device were also excluded.

The gingival sulcus fluid was taken for examination of IL-1B levels in the same jaw on both sides. The test group was the gingival crevicular fluid taken from the tooth of one region, while the control group was taken from the contralateral region. Gingival sulcus fluid was taken twice in each patient, on day 0 (D0) and the $30^{\text {th }}$ day (D30) for both groups. The gingival sulcus collected from 22 samples were then calculated simultaneously to be analysed for the comparison of IL-1B levels after day 30 using the ELISA test in the laboratory. The test group in this study was the group that was treated with scaling, root planing, and being applied with apatite carbonate membrane gelatin; while the control group was the group that performed the scaling and root planing only. At day 0 (D0; the first-day of the patient visit) was taken for gingival crevicular fluid, scaling and root planing, and applied with apatite carbonate membrane gelatin. At the $30^{\text {th }}$ day of the patient's control, the gingival crevicular fluid was retaken. 
Clinical parameters to be tested in this study were IL-1B levels in the gingival crevicular fluid. The subjects who met the inclusion criteria was performed supragingival plaque removal by the researchers only on the examined teeth. The cotton roll was dried the gingiva on the spesific tooth, and the gingival crevicular fluid was obtained at the pocket depth of $\geq 5 \mathrm{~mm}$ both on the test and control groups with a paper point for $1 \mathrm{~min}$, then put into the Eppendorf tube. The operator performed scaling and root planing afterwards, while the assistant operator performed the application of the apatite carbonate gelatin to each pocket, because the operator should not know the test area and the control area of the treatment (the operator, patient, and laboratory operator should kept unaware). Furthermore, the test and control areas were covered with the periodontal pack for one week.

Eppendorf tube containing paper point was then taken to the Clinical Pathology Laboratory of Hasan Sadikin Hospital with a coolbox to be centrifuged and stored in a refrigerator at the temperature of $-80^{\circ} \mathrm{C}$, until the prior time to performed the ELISA test simultaneously to observe the IL-1 1 levels.

Statistical analysis of the data was performed to compare the mean difference of IL-1B between the treatment and the control groups, using the pairwise t-test, or Wilcoxon test if the data were not normally distributed. The significance of the test result was determined on the $p$-value $<0.05$.

\section{RESULTS}

Twenty-two chronic periodontitis patients at the Periodontics Clinic of Universitas Padjadjaran Dental Hospital were involved as participants and divided into two groups, each totalling 11 people. Table 1 presented the respondents' characteristics. The average age of respondents was 48.6 years, with a range of $36-65$ years. The highest education level of all respondents was secondary education, with as many as 10 people. More respondents found to be occupied than unemployed. The teeth composition of the respondents was generally normal, which found in as many as 17 people, crowded in 3 people, and diastema in 2 people.
The results of the IL-1B examination based on the Wilcoxon test is presented in Table 2. Before and after treatment, each group had a significant decreasing level of IL-1B ( $p<0.001)$. Based on the paired t-test results showed in Table 3, no significant difference analysed $(p>$ 0.05 ). The decreasing IL-1B percentage in the treatment group was $39.23 \%$, while the control group was $36.95 \%$. The difference in IL-1B level percentage reduction was found to be statistically insignificant $(p>0.05)$, but tend to show a higher reduction in the treatment group. Based on the comparison between IL-1B level in the treatment group and control group can be seen that apatite carbonate membrane gelatin application

Table 1. Characteristics of respondents

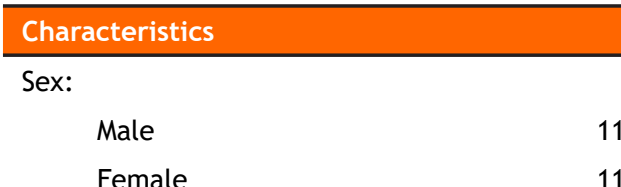

Age (years):

$$
\begin{aligned}
& \text { (SD) : } 48.6(9.0) \\
& \text { Range: } 36-65
\end{aligned}
$$

Education Level:

$\begin{array}{ll}\text { Elementary school } & 4 \\ \text { Junior High School } & 10 \\ \text { Senior High school } & 8\end{array}$

Work:

Occupied 17

Unemployed 5

The arrangement of teeth:

$\begin{array}{ll}\text { Normal } & 17 \\ \text { Crowding } & 3 \\ \text { Diastema } & 2\end{array}$

Duration of pain (month):

(SD): 13.0 (11.6)

Note: Median $=10 ;$ Range $=1-36 ; n=22$

Table 2. Decreasing levels of IL-1B in the test and control groups

\begin{tabular}{lllll}
\hline \multicolumn{5}{c}{ IL-1 B (pg/ml) levels } \\
\hline Group & & H0 & H30 & P*value \\
\hline Test & Average (SD) & $4.44(1.59)$ & $2.88(2.45)$ & $<0.001$ \\
$(\mathrm{n}=22)$ & Median & 4.40 & 2.50 & \\
Control & Average (SD) & $4.58(1.89)$ & $2.94(2.43)$ & $<0.001$ \\
$(\mathrm{n}=22)$ & Median & 4.60 & 2.49 & \\
T test vs control & & & \\
Comparation & $\mathrm{p}^{*}=0.314$ & $\mathrm{p}^{*}=0.770$ & \\
\hline
\end{tabular}

Note: *Wilcoxon test 
Table 3. Percentage of IL-1B levels in the test and control groups

\begin{tabular}{|c|c|c|c|}
\hline \multicolumn{4}{|c|}{ IL-1 B (pg/ml) levels } \\
\hline Group & & Difference (D0-D30) & $\%$ \\
\hline \multirow[t]{2}{*}{ Test $(n=22)$} & Average (SD) & $1.56(1.57)$ & $39.23(31.73)$ \\
\hline & Median & 1.5 & 42.06 \\
\hline \multirow[t]{2}{*}{ Control $(n=22)$} & Average (SD) & $1.64(1.45)$ & $36.95(28.82)$ \\
\hline & Median & 1.93 & 40.24 \\
\hline \multicolumn{2}{|c|}{ Test vs control comparation } & $p^{* *}=0.587(p>0.05)$ & $\mathrm{p}^{* *}=0.574(\mathrm{p}>0.05)$ \\
\hline
\end{tabular}

Note: *paired t-test

decreased the levels of IL-1B in the gingival sulcus fluid of chronic periodontitis patients, both in the treatment group and control group, although not significantly different.

\section{DISCUSSION}

The results obtained in this study showed a significant improvement observed from the significant decrease of IL-1B levels on day 0 until day 30 in both groups. This result was consistent with the results of the studies conducted by $\mathrm{Hou}^{10}$, in which the IL-1B levels were reduced one month after scaling. Although the decrease in IL$1 B$ level in both groups were similarly significant, the comparison of the level changes between the test group and the control group was not statistically significant. In other words, the results of adjunctive therapy with apatite carbonate membrane have no better results than the control group.

Periodontal treatment is successful if the improvement of the inflammatory response occurs, characterised by decreasing of IL-1B. ${ }^{11}$ IL-1B triggers an inflammatory response which activates osteoclasts thus plays an essential role in bone remodelling. ${ }^{12}$ The apatite carbonate membrane gelatin is a synthetic product of a thin gelatin layer containing apatite carbonate. The apatite carbonate gelatin material has been reported in several studies on its excellent biocompatibility, osteoconductivity, and increases the local concentration of calcium and phosphate ions needed for bone tissue regeneration. ${ }^{8}$

The period of 30 days in this current study was selected because, in a study comparing the effectiveness of chlorhexidine varnish and chips in chronic periodontitis patients, significant differences were seen only in the $30^{\text {th }}$ day after treatment, while the results at three months and six months after treatment did not show any differences. ${ }^{11}$

The apatite carbonate membrane gelatin can be well biodegraded and have excellent biocompatibility, resembling a bone connective tissue collagen matrix, which may initiate increased attachment and cell spread, and may also increase proliferation of fibroblasts. ${ }^{11,13}$ The gelatin concentration in the apatite carbonate membrane used in this study was in the ratio of 7:3. This composition was appropriate and resulting in a large porosity that increases cell proliferation and facilitates the transport of oxygen and also nutrient supply. Thus, the adjacent tissues will have a tensile strength in the normal range, because, with the weakness of the membrane, it will further limit the ability of the application, and become the burden for the body. ${ }^{14,15}$

One of the shortcomings of this study was the measurement of gingival sulcus fluid volume did not carry out with the Perio-tron device. Periotron is a tool that can be used in research to check the levels of IL-1B. This device is functioned to measure the fluid volume of the gingival sulcus accurately, and its value has been set in the calibration function using the human se-rum as a standard. ${ }^{16}$ Thus the results of the measurement will be more equivocal.

\section{CONCLUSION}

Application of apatite carbonate membrane gelatin able to reduce the IL- $1 B$ levels in the gingival sulcus fluid of chronic periodontitis patients, as well as in the patients with no adjunctive therapy in the control group. The decreaseing level of IL-1B showed a higher percentage in patients with application of apatite carbonate membrane gelatin, but only slightly different with the patients in the control group. 


\section{REFERENCES}

1. Addy M. Tooth brushing, tooth wear and dentine hypersensitivity-Are they associated? Int Dent J. 2005; 55(4 Suppl 1): 261-7. DOI: 10.1111/j.1875-595x.2005.tb00063.x

2. Reis C, da Costa AV, Guimarães JT, Tuna D, Braga AC, Pacheco JJ, et al. Clinical improvement following therapy for periodontitis: Association with a decrease in IL-1 and IL-6. Exp Ther Med. 2014; 8(1): 323-7. DOI: $10.3892 /$ etm.2014.1724.

3. Ekaputri S, Masulili SLC. Cairan sulkus gingiva sebagai indikator keadaan jaringan periodontal. Maj Ked Gi Ind. 2010; 17(1): 748. DOI: $10.22146 /$ majkedgiind.16069.

4. Shyu KG, Choy CS, Wang DCL, Huang WC, Chen SY, Chen $\mathrm{CH}$ et al. Change of scalinginduced proinflammatory cytokine on the clinical efficacy of periodontitis treatment. Sci World J. 2015; 2015: 289647. DOI: 10.1155/2015/289647

5. Bathla S, Bathla M. Periodontics revisited. $1^{\text {st }}$ ed. New Delhi: Jaypee Brother Medical Publisher (P) Ltd.; 2011.

6. Heidari $Z$. The association between proinflammatory gene polymorphisms and level of gingival tissue degradation in chronic periodontitis. Gene Cell Tissue. 2014; 1(2): e21898. DOI: $10.17795 /$ gct-21898

7. Grigoriadou ME, Koutayas SO, Madianos PN, Strub JR. Interleukin-1 as a genetic marker for periodontitis: Review of the literature. Quintessence Int. 2010; 41(6): 517-25.

8. Wahyudi IA, Nurwadji LM. The effect of non freeze-dried hydrogel-CHA on Fibroblast Proliferation. J Dent Ind. 2014; 22: 89-93. DOI: $10.14693 /$ jdi.v21i3.226.

9. Takemoto S, Kusudo Y, Tsuru K, Hayakawa S, Osaka A, Takashima S. Selective protein adsorption and blood compatibility of hydroxy-carbonate apatites. J Biomed Mater Res A. 2004; 69(3): 544-51. DOI: $10.1002 /$ jbm.a.30039.
10. Hou LT, Liu CM, Rossomando EF. Crevicular interleukin-1B in moderate and severe periodontitis patients and the effect of phase I periodontal treatment. J Clin Periodontol. 1995; 22(2): 162-7. DOI: $10.1111 / \mathrm{j} .1600-$ 051x.1995.tb00128.x

11. Jagadish Pai BS, Rajan SA, Srinivas M, Padma R, Suragimath G, Walvekar A, et al. Comparison of the efficacy of chlorhexidine varnish and chip in the treatment of chronic periodontitis. Contemp Clin Dent. 2013; 4(2): 156-61. DOI: 10.4103/0976-237X.114848.

12. Kaya FA, Hamamci N, Basaran G, Dogru M, Yildirim TT. TNF- a , IL-1 B AND IL-8 Levels in Tooth Early Levelling Movement Orthodontic Treatment. J Int Dent Med Res. 2010; 3(3): 116-121.

13. Ana ID, Matsuya S, Ishikawa K. Engineering of carbonate apatite bone substitute based on composition-transformation of gypsum and calcium hydroxide. Engineering. 2010; 2(5): 344-52. DOI: 10.4236/eng.2010.25045

14. Narbat MK, Hashtjin MS, Pazouki M. Fabrication of porous hydroxyapatite-gelatin scaffolds crosslinked by glutaraldehyde for bone tissue engineering. Iran J Biotechnol. 2003; 4(1): 54-60.

15. Ardhani R, Setyaningsih, Hafiyyah OA, Ana ID. Preparation of carbonated apatite membrane as metronidazole delivery system for periodontal application. Key Engineering Mater. 2016; 696: 250-8. DOI: 10.4028/www. scientific.net/kem.696.250

16. Lu HK, Chei CJ. Efficacy of subgingivally applied minocycline in the treatment of chronic periodontitis. J Periodontal Res. 2005; 40(1): 20-7. DOI: $10.1111 / j .1600-0765.2004 .00763 . x$

17. Masada MP, Persson R, Kenney JS, Lee SW, Page RC, Allison AC. Measurement of InterleukinIL-1 $\alpha$ and $-1 B$ in Gingival Crevicular Fluid: Implications for The Pathogenesis of Periodontal Disease. J Periodontol Res. 1990; 25(3): 156-63. DOI:10.1111/j.1600-0765.1990. tb01038.x 